\title{
Os adolescentes e a leitura literária por opção ${ }^{1}$
}

\section{Teenagers and the reading of literature by choice}

\author{
Aline de Mello Sanfelici ${ }^{2}$ \\ Fábio Luiz da Silva ${ }^{2}$
}

\begin{abstract}
RESUMO
Este estudo investiga o comportamento literário de adolescentes que buscam literatura por opção própria, ou seja, além daquela exigida pela escola. Analisando questionários respondidos por 92 alunos, com idade entre 10 e 17 anos, na cidade de Londrina, Paraná, buscamos traçar um perfil dos leitores voluntários, assim como observar diferenças entre os interesses de leitura dos jovens e os interesses de ensino do currículo escolar. A partir dessas constatações, finalizamos nosso estudo trazendo algumas considerações práticas sobre como mediar harmoniosamente o conflito entre essas diferenças de interesses, tomando como ponto de partida o trabalho de Jobim (2009), entre outros. Destacamos que as considerações apresentadas podem aplicar-se a outros contextos dentro e fora do Brasil.
\end{abstract}

Palavras-chave: adolescentes; leitura literária; conflito de interesses.

\begin{abstract}
This study investigates the literary behavior of teenagers who seek literature by choice, that is beyond the readings required by school. By analyzing questionnaires answered by 92 students with ages ranging from 10 to 17 , in the city of Londrina, Paraná, we established a profile of the volunteer readers. We also observed the differences between the reading interests of the youth and those of the school curriculum. Based on these observations,
\end{abstract}

DOI: $10.1590 / 0104-4060.38946$

1 Trabalho realizado com apoio financeiro da Coordenação de Aperfeiçoamento de Pessoal de Nível Superior, a partir do Programa Nacional de Pós-Doutorado/CAPES.

2 Universidade Norte do Paraná. Pró-Reitoria de Pesquisa e Pós-Graduação. Londrina, Paraná, Brasil. Rua Marselha, nº 591 - Jardim Piza. CEP: 86041-120. E-mails: alinefelice@gmail. com; fabio.luiz1@unopar.br 
we concluded our work bringing some practical ideas on how to peacefully attune the conflict between the differences of interests, using as starting point the work of Jobim (2009), amongst others. We highlight that these concepts may also apply to other contexts both within and outside Brazil.

Keywords: teenagers; reading of literature; conflict of interests.

\section{Considerações preliminares}

A pesquisa "Retratos da Leitura no Brasil" é um projeto ambicioso e relevante para entendermos a temática da leitura pelo país afora em suas características, problemas, tendências, e desafios. Gomes (2012), em seu artigo a partir da última edição dessa pesquisa, constata que os jovens são a maior população leitora no país, mas seu hábito de leitura acaba com a saída da escola: “[...] se não são obrigados, se não são estimulados, eles param de ler. Ao sair da escola, o jovem perde a ambiência leitora, o grupo de amigos e a convivência com os livros". (GOMES, 2012, p. 129). O foco de nosso estudo, então, é justamente a questão da leitura literária de jovens, especificamente aquela feita por opção, e não por imposição curricular.

A leitura literária realizada pelos adolescentes no contexto escolar costuma ser ditada por questões de tradição: são incluídas na seleção de leituras do currículo as obras consideradas clássicas ou canônicas, pertencentes ao chamado patrimônio literário nacional, e que são também, predominantemente, os textos recorrentes em exames de vestibular. Deste modo, os adolescentes, na escola, encontram leituras não necessariamente da ordem de seu interesse pessoal e, muitas vezes, até mesmo textos razoavelmente distantes de seu mundo particular - apesar de elementares para a sua formação literária. Nestas circunstâncias, muitos adolescentes optam por buscar outros tipos de leituras em suas horas livres, trocando José de Alencar e Guimarães Rosa pela saga do Harry Potter ou as aventuras vampirescas da série Crepúsculo. É justamente esse tipo de escolha que aqui nos interessa.

Nesta pesquisa, fazemos um levantamento e buscamos traçar um breve perfil a respeito de um grupo de adolescentes e suas buscas por literatura por escolha própria. Nosso primeiro objetivo é compreender esse perfil e processo desde sua fase inicial, das motivações e tipos de livros lidos, até a fase pós-leitura, considerando o que é feito com o material lido espontaneamente pelo jovem, em termos de compartilhamento das histórias e discussões agregadas pelas obras. A partir do entendimento deste perfil e processo, almejamos um 
outro objetivo, o de refletir sobre o conflito entre os interesses peculiares dos alunos e as reais exigências escolares, apontando alternativas para a mediação harmoniosa de tal conflito, com o intento de satisfazer tanto os alunos adolescentes quanto seus professores e escolas.

Cumpre destacar, nestas considerações preliminares, que neste trabalho não nos cabe emitir qualquer avaliação ou julgamento de valor a respeito da qualidade estética, literária e cultural das obras escolhidas espontaneamente pelos jovens; nosso foco, reiteramos, está nas questões de autoidentificação, interesses particulares e pessoais e demais fatores de atração dos alunos para certas leituras, diferentes das selecionadas pela escola, seguido do debate sobre como pacificar a relação entre o que a escola exige e o que interessa verdadeiramente ao jovem leitor.

\section{A relação entre adolescentes e literatura: por que eles buscam o que buscam?}

Uma indagação motivadora desta pesquisa diz respeito ao que ocorre no ambiente escolar e que leva os jovens hoje em dia a movimentarem tão intensamente o mercado editorial, como consumidores ativos e numerosos de literatura específica para sua faixa etária. Os jovens buscam em ambientes fora da escola a satisfação de suas necessidades e expectativas no que tange à leitura literária. Aparentemente, e de modo bastante simples, podemos dizer que isso ocorre dado o desencontro entre os interesses da escola e os dos adolescentes. O estudo de Faria (1995), por exemplo, sinaliza a distância maciça entre os currículos escolares para a literatura e os sujeitos-alvo deste currículo, isto é, os próprios leitores-alunos. Como a pesquisadora afirma, "[...] a leitura literária é feita por imposição do professor, sem levar em conta as tendências pessoais dos alunos, suas preferências e expectativas". (FARIA, 1995, p. 35). Esse quadro, constatado há aproximadamente 20 anos atrás, continua atual no cenário educacional, uma vez que, via de regra, aos alunos não é dada qualquer voz ou possibilidade de consulta na construção dos currículos e seleção das leituras literárias na escola.

Além disso, Faria (1995) também aponta que, considerando as obras efetivamente lidas na própria escola, os adolescentes não têm espaço para expressar suas opiniões pessoais a respeito das leituras, uma vez que os professores costumam aplicar questionários padronizados e fechados, iguais para toda a turma, e passíveis de verificação rápida em termos de "certo" e "errado". Com constatações semelhantes, Cosson (2011) discute como as cotidianas fichas de 
leitura acabam por " $[\ldots]$ cercear a criatividade ou podar o prazer da leitura, [...] [sendo] no geral voltadas para a identificação ou classificação de dados, servindo de simples confirmação da leitura feita". (COSSON, 2011, p. 22). Zilberman $(2009$, p. 35) afirma que se a interpretação é condenada a respostas fechadas via fichas de leituras, "o resultado [é] a anulação da experiência pessoal [...] com o texto". Outros pesquisadores, como Cereja (2005), também reiteram que as atividades normalmente corriqueiras nas aulas de literatura, focadas em identificação de gêneros e traços de escolas literárias, aniquilam o poder de exploração dos muitos potenciais do texto literário, texto esse que, paradoxalmente, ocupa um lugar periférico na própria aula de literatura.

Acreditamos que esta falta de espaço para discutir as obras em nível mais subjetivo e de enriquecimento pessoal, bem como os tipos de atividades normalmente feitas (como as fichas de leituras) possam ser fatores que motivem os jovens a buscarem as literaturas que eles buscam espontaneamente. Isso se daria porque esta literatura opcional, extraclasse, poderia ser livremente compartilhada. Em outras palavras, se vários amigos leem a mesma obra por livre interesse, eles podem criar a oportunidade de, em seu espaço fora da escola, discorrer sobre sua identificação com o personagem ou a trama, seu sentimento em relação à leitura e às problemáticas tratadas na obra, e demais assuntos que dentro da sala de aula são normalmente silenciados. A respeito desta "liberdade" que propulsiona a leitura extraclasse, Bamberger (2000, p. 31) afirma que "[...] o que leva o jovem a ler não é o reconhecimento da importância da leitura, e sim várias motivações e interesses que correspondem à sua personalidade e ao seu desenvolvimento intelectual". Então, se na escola não há espaço para certas leituras e temáticas ou para discussões subjetivas e críticas, é na leitura literária por opção, não imposição, que o jovem encontra esse espaço.

Outro fator atrelado ao ambiente escolar, especificamente, e que afeta de modo direto a relação entre os adolescentes e a leitura de literatura trata da questão dos acervos, bibliotecas e demais espaços e momentos oferecidos pelas instituições de ensino para o encontro do aluno com as obras literárias. No que tange a este ponto, Cunha (2012), analisando dados da pesquisa "Retratos da Leitura no Brasil", argumenta que os dados dos entrevistados apontam para a urgência da biblioteca escolar " [...] se repensar, modernizar-se com relação ao acervo, espaço, pessoal e projetos, para realmente cumprir sua função de convidar à permanência e oferecer-se como lugar de leitura". (CUNHA, 2012, p. 88). Outro estudo relevante neste quesito é o de Silva (2013). Primeiramente, no âmbito nacional, Silva lembra a Avaliação das Bibliotecas Escolares no Brasil, de 2011, que constatou que: 
[...] a maioria dos espaços denominados bibliotecas gerais, pelos agentes de pesquisa, não se caracteriza como tal. Em maioria, são espaços improvisados que pouco permitem que os usuários pratiquem diferentes tipos de leitura. Quando há mesas coletivas, estas são usadas por alunos para "pesquisas escolares" indicadas por professores. (BRASIL, Ministério da Educação, 2011, p. 63, citado por SILVA, 2013, p. 358).

Já no âmbito local, Silva observa que, em Londrina, a estrutura física das bibliotecas escolares era "improvisada, caótica", e o professor que lá atuava era desprestigiado e isolado, como se a biblioteca "[...] estivesse num mundo à parte da escola e das questões pedagógicas dela”. (SILVA, 2013, p. 359). Isso Silva constatou como realidade pelo menos até 2002, antes de iniciar seu projeto "Palavras Andantes", posteriormente reconhecido nacionalmente com o prêmio Vivaleitura, em 2008. Mesmo com os avanços locais a partir do projeto, e considerando também o âmbito nacional, o cenário (ainda) de necessidade de revitalização da estrutura física e de melhorias no acervo e nas ações de envolvimento da biblioteca com a comunidade escolar sugere eventuais dificuldades de aproximação dos adolescentes com a literatura no próprio ambiente escolar. Este pode ser um outro fator motivacional para os jovens buscarem outras opções de literatura em suas horas livres e fora da escola: eles encontrariam em livrarias, em e-books na internet e em feiras de livros o que a biblioteca escolar muitas vezes não dá, ou seja, obras contemporâneas, ou edições mais atualizadas, e em volumes mais atraentes.

Biasioli (2007) fornece outra questão a respeito da relação entre adolescentes e literatura que consideramos importante. Conforme a autora, "[...] em diversos veículos de comunicação renomados, pouca atenção é dada à literatura infanto-juvenil”. (BIASIOLI, 2007, p. 95). Utilizando pesquisa de Ceccantini (2004), constata-se que nestes veículos “[...] não há absolutamente colunas que, de forma sistemática e com periodicidade regular, se dediquem à crítica das obras infanto-juvenis lançadas no mercado" (CECCANTINI, 2004, p. 34, citado por BIASIOLI, 2007, p. 95-96), tendo-se, no máximo, divulgação de lançamento das obras ou então comentário em revistas específicas para professores. Entendemos que estes pontos podem afetar os adolescentes no sentido deles não terem muitas referências e fontes de informação, e, assim, ficam mais vulneráveis ao mercado editorial e suas literaturas de massa e atraídos pelas sagas de aventuras amplamente popularizadas e glamourizadas por suas versões cinematográficas. Tal vulnerabilidade pode ter um papel crucial no impulso dos adolescentes em buscar essas literaturas, não encontradas no espaço escolar, e que ocupam cada vez mais espaço nas estantes e conversas dos jovens de hoje. 
Ao mesmo tempo, porém, a pesquisa de Cereja (2005) indica que os adolescentes, especialmente em vias de terminar o Ensino Médio, além de lerem "obras do momento, divulgadas pelos meios de comunicação", tem como obras citadas como preferidas, "[...] em grande parte [...] os mesmos 'clássicos' regularmente apontados pelos professores ou solicitados pelos vestibulares". (CEREJA, 2005, p. 34). Conforme o estudioso discute, este fato sinaliza o papel da escola "[...] na construção do gosto literário e na formação de 'comunidades de leitura', constituídas não apenas de alunos, mas também de outras pessoas que com eles se relacionam e têm acesso aos livros". (CEREJA, 2005, p. 34). Observa-se que mesmo com as dificuldades e limitações do trabalho com a literatura na escola, esta ainda consegue exercer um papel relevante no que diz respeito ao acesso e à formação ampla do leitor.

Por fim, a respeito da literatura de massa amplamente consumida pelos jovens, ela tem sido fonte de diversos estudos recentemente, uma vez que é responsável por parte do aquecimento do mercado editorial, tanto infanto-juvenil quanto adulto. Segundo Lourenço (2010), a literatura de massa tem sido a iniciação literária de muitos adolescentes, e no caso dos sujeitos de sua pesquisa, os resultados mostram que, dos livros lidos não pedidos pela escola, a maioria é romance estrangeiro traduzido para o português. Isso inclui tanto obras clássicas, i.e., consideradas cultas, como de Mark Twain, quanto - e em maior número - literatura de massa, como $O$ mundo de Sofia, Marley e eu, $O$ código da Vinci, entre outros. Segundo Lourenço (2010), as justificativas para essas leituras de massa tão presentes no gosto dos adolescentes incluem serem textos "[...] fáceis de ler, leitura rápida, enredos interessantes, assistiu ao filme, considerou a capa atraente, indicação de amigos ou familiares, propagandas". (LOURENÇO, 2010, p. 376). Mafra (2003), ao analisar a literatura de massa e o público juvenil, acrescenta que, dentre outras justificativas para buscar esse tipo de leitura, há a necessidade de ler, culturalmente associada com maior intelecto e chances de ascensão econômica e social.

Seja qual for o motivo, é notável que os adolescentes têm lido, tanto na escola quanto à revelia dela. Na visão de Chartier (2009, p. 103-104), “[...] aqueles que são considerados não leitores lêem, mas lêem coisa diferente daquilo que o cânone escolar define como uma leitura legítima". Como afirmamos anteriormente, não é nosso interesse, aqui, emitir julgamentos de valor a respeito do que os adolescentes leem, mas tão somente entender o perfil destes alunos a partir do que leem por opção e discutir isso à luz das aulas de literatura na escola. Isto posto, vamos agora, então, investigar nosso contexto e corpus específico, de modo a entender o processo de buscar leituras próprias, suas motivações e resultados pessoais, bem como discutir formas de alinhar esses interesses dos jovens com as necessidades da escola, mediando o conflito resultante das diferenças entre as leituras obrigatórias e aquelas que de fato atraem os adolescentes. 


\section{Leitores por opção: nossa coleta de dados}

Detalharemos a seguir os procedimentos principais para conduzirmos nossa pesquisa. Convidamos alunos do Ensino Fundamental II, matriculados entre o $6^{\circ}$ e o $9^{\circ}$ ano do Colégio de Aplicação Pedagógica da Universidade Estadual de Londrina, no Paraná, para participar do estudo. A escola está localizada na região central da cidade e oferece ensino desde a Educação Infantil até o Ensino Médio, inclusive profissionalizante. Os alunos participantes da pesquisa formam um grupo de faixa etária variada, abrangendo dos 10 aos 17 anos de idade.

Distribuímos entre os alunos um questionário composto por oito questões. As perguntas estavam centradas nas leituras literárias de escolha própria dos estudantes, incluindo motivação para as escolhas, quantidade e tipos de livros favoritos e compartilhamento de leituras ou participação em grupos e páginas de literatura em redes sociais on-line. Um total de 92 questionários foi respondido de modo presencial em sala de aula, ou então on-line e enviado por e-mail.

É interessante destacar que nossa análise se dá a partir das respostas do questionário, pois, seguindo Soares (2006), entendemos as opiniões de crianças e adolescentes como expressões legítimas de sujeitos que são, antes de tudo, atores sociais, e, portanto, possuem voz, visibilidade e sensibilidade próprias, e são capacitados psicologicamente a articular suas opiniões e ações, contribuindo e participando ativamente de reflexões que possam ter efeitos em suas próprias vidas e contextos.

Visando contemplar nosso objetivo de contribuir para o entendimento do perfil desses jovens leitores e para a promoção de melhorias nas relações entre os interesses de leitura dos adolescentes e os interesses de ensino do currículo escolar, partimos agora para nossas reflexões baseadas nas respostas dos alunos.

\section{Algumas reflexões sobre os adolescentes e a literatura}

Nesta seção, apresentamos nossas análises a partir da coleta de dados feita. Observando os questionários recebidos, uma primeira constatação é evidente e até mesmo previsível: nem todos adolescentes se interessam por literatura. Não é tão alto o número de alunos que declararam explicitamente não gostar de ler ou que demonstraram, em respostas curtas, negativas e/ou desinteressadas, que preferem outras atividades à leitura literária. Dos 92 questionários, 20 
tiveram esse perfil, ou seja, aproximadamente $22 \%$ dos entrevistados. Algumas respostas sinalizam os motivos desse desinteresse. Um deles é a concepção de literatura como algo necessariamente sério (e, portanto, entendido pelo jovem como próximo a uma atividade escolar), e não como uma oportunidade de entretenimento e lazer, ou de aprendizagem a partir da diversão da imaginação, por exemplo. Algumas respostas ilustrativas deste ponto seriam: "eu não gosto de livros, gosto de diversão", implicando que a literatura não pode ser divertida; e "leio livro quando não há nada para fazer", resposta compartilhada por quatro alunos do grupo que não lê, indicando que para o jovem há muitas outras atividades preferíveis à literatura. Também como justificativa para não ler, outras respostas foram: "não vou à biblioteca", "não leio porque eu sou uma pessoa muito ocupada", e "não gosto de ler muito, eu só pego o livro e desisto de ler", todas sinalizando o perfil de desinteresse e falta de motivação.

Considerando que são diversos os fatores que levam um jovem a não gostar de literatura (como falta de incentivo e hábito familiar, traços de personalidade própria, outros interesses individuais, etc.), entendemos como absolutamente normal encontrar no grupo de entrevistados atitudes como as demonstradas nas respostas acima. De todo modo, nosso interesse maior é no grupo de adolescentes que efetivamente fazem leitura de literatura por opção, por gosto, por vontade própria. Então, é para esse grupo que olharemos a partir de agora.

No grupo, um dado bastante variado nas respostas foi a quantidade de livros lidos. Enquanto alguns alunos declararam que leem 1 livro por mês, ocorreram respostas declarando ler até 50 ou 60 livros por ano, enquanto outros afirmaram que leem em torno de 5 por ano. Por mais que a assiduidade de leitura varie, resultando em quantias bastante discrepantes quando olhamos para o grupo como um todo, podemos observar vários pontos de confluência no perfil destes alunos, a partir das respostas dadas para as outras questões, como veremos a seguir.

A respeito dos gêneros literários mais lembrados, foram citados com expressiva maior assiduidade aventuras em séries e trilogias, ficção científica, fantasia e romance. Algumas menções em menor quantidade foram feitas, também, a suspense/mistério, terror e mitologia. E até 5 alunos citaram a Bíblia, poesia, fábulas, mangá, gibis, autoajuda, crônica, policiais, culinária, e "livros que depois viraram filmes". Desconsiderando classificações restritivas de gêneros literários, o que é relevante comentar, neste quesito, é que os interesses de leitura são variados e abrangentes tanto quanto o grupo de entrevistados é composto por sujeitos individuais com motivações e paixões próprias. Ao mesmo tempo, impressiona o quanto os jovens se envolvem com histórias de aventuras, ficção científica, fantasia e romance: dos 72 questionários deste grupo, 2 não especificaram gênero literário e apenas 3 citaram gêneros que não fossem aventura, ficção, fantasia ou romance. Todos os outros 67 questionários, ou seja, 93\% dos 
entrevistados que são leitores literários por opção, mencionaram pelo menos um desses gêneros mais recorrentes, se não vários deles além de outros não tão recorrentes. Esse índice sinaliza o tipo de leitura que os atrai: especialmente aquelas que se distanciam da realidade cotidiana e que empolgam pela emoção e suspense da aventura ou pelo drama retratado na história.

Podemos relacionar esses dados dos gêneros favoritos com as motivações para leitura. As respostas sobre o que os leva a ler literatura livremente indicam, além de individualidades previsíveis, muitas motivações semelhantes. Os itens em comum de motivação incluem: o conteúdo da história e a chance de conhecer novas histórias; oportunidade de entretenimento; incentivo por parte de familiares (é especialmente lembrada a figura da mãe); conhecer sobre a cultura ou época do livro; interesse pela série de TV ou filme inspirado na obra literária; e aprender mais sobre a palavra de Deus (para quem citou a Bíblia). Alguns comentaram também a oportunidade de aprendizagem, de melhoria na habilidade leitora e do vocabulário, o que mostra conscientização de que a literatura pode enriquecer o conhecimento de mundo (com novas histórias e falando sobre outras realidades e épocas), como também seu desempenho no dia a dia, incluindo na escola. Mas a principal motivação, citada por aproximadamente metade do grupo, relaciona-se com imaginação. Algumas respostas foram: "fico me imaginando como personagem", "gosto de ler para sair um pouco do mundo real", "fico lendo para tentar imaginar o que eu passaria se fosse o personagem", "a melhor parte é se desligar de tudo ao seu redor", "eu amo ler, gosto de viajar nas histórias", e "a minha imaginação vai à loucura".

Tendo visto a quantia de livros lidos, os gêneros favoritos e as motivações principais, veremos agora a questão de compartilhamento após a leitura. De todo o grupo em questão, a maioria não relaciona a literatura com suas redes sociais on-line. Quando perguntados a respeito, apenas 21 dos 72 alunos (aproximadamente $30 \%$ ) declararam que seguem algum grupo ou página relacionada com literatura no Facebook ou outra rede semelhante. As páginas mais citadas foram: Livraria Saraiva, Eu me chamo Antônio, Literatortura, Uma odisseia na estante, e várias específicas de obras como da saga Harry Potter, Diário de Anne Frank, The vampire diaries, além de quatro alunos que afirmaram seguir páginas, mas não lembravam os nomes delas no momento. Mesmo sendo minoria, o índice de $30 \%$ é significativo no sentido de que a internet tem ocupado um espaço cada vez maior no universo do jovem, e esse número pode aumentar à medida que os jovens usem mais e mais a tecnologia. Acreditamos que compartilhar sobre literatura neste espaço virtual é importante para dar visibilidade ao próprio ato da literatura como uma atividade feita por escolha própria, e devidamente demonstrada perante o grupo de amigos e redes de contatos nas páginas de relacionamento. 
Já quando perguntados sobre se compartilham as histórias após ler o livro, as respostas variaram entre não comentar com ninguém; conversar com amigos que já leram a história; conversar com amigos que não leram, de modo a recomendar a obra "sem dar 'spoiler"'; e comentar com familiares. Uma aluna ainda citou compartilhar frases e trechos dos livros nas páginas de relacionamento, que é um meio de incitar a curiosidade e, de certo modo, recomendar a leitura. $\mathrm{O}$ fato de a maioria conversar a respeito das obras é muito positivo, pois indica satisfação na autoidentificação do jovem como sendo um leitor assíduo e que lê por opção, além do potencial de motivação para formar outros leitores e fomentar uma relação com familiares, amigos ou colegas a partir de interesses estabelecidos em comum. Já para os que não compartilham nada a respeito da obra e do hábito de ler, podemos atribuir esse fator a questões variadas, não investigadas no escopo do nosso questionário, como, por exemplo, uma personalidade mais retraída. Em outras palavras, não deve surpreender nem espantar que, entre adolescentes que leem, nem todos tenham interesse em falar a respeito disso.

A seguir, tentaremos apresentar ideias para aproximar os interesses desses alunos com os interesses da escola, que tradicionalmente se concentram no ensino de obras canônicas e com preocupação central nas futuras exigências de exames de vestibular. Como destacamos no início deste estudo, a seleção de leituras obrigatórias imposta pela escola, por ser voltada ao cânone estabelecido e aos exames de vestibular, dificilmente dialoga com os reais interesses dos alunos. Isso gera um conflito, à medida que os adolescentes ou não gostam de ler (e nas leituras obrigatórias encontram mais motivos para o desgosto, dada a distância entre interesses), ou gostam de ler, mas não necessariamente se empolgam com o material determinado pelo currículo. Fica posto então o desafio de aproximar os interesses discrepantes dos jovens e dos currículos, para que se crie uma relação mais produtiva e afinada entre os jovens e a literatura na escola.

Uma alternativa de lidar com esse desafio pode ser concebida a partir do trabalho de Jobim (2009). O autor declara o seguinte:

[...] acredito que, a partir do momento em que despertamos a atenção do educando para a Literatura, a partir de textos mais "fáceis", poderemos, com melhor efeito, introduzi-lo no mundo das linguagens mais "difíceis" (por exemplo, a do Barroco), ou no mundo dos temas que não fazem parte (ainda) de seu universo. (JOBIM, 2009, p. 117).

Em outras palavras, seria possível utilizar a literatura que efetivamente interessa aos jovens como gancho, ponto de partida, para que se forme o leitor, 
que se desenvolva o gosto pela leitura e pela literatura, e então, a partir disso, partir-se para a literatura tradicionalmente exigida na escola. Como coloca Jobim (2009, p. 117), “[...] ao levar em consideração as características de seu público, o professor poderá escolher os textos que 'interessem', ou seja, que possibilitem a discussão de temas importantes para a experiência do aluno". Deste modo, usando o que é interesse do aluno como espécie de gancho, teria-se uma possibilidade para lidar com o problema posto.

Outra alternativa, claro, seria justamente rever, pelo menos em parte, o que a escola tradicionalmente exige. Poderia-se, neste caso, buscar um diálogo entre o tradicional e o novo, o canônico e o desconhecido, o clássico e a saga literária em evidência - não desconsiderando completamente o que costuma ser ensinado e começando "do zero", mas sim buscando uma parceria, um diálogo entre texto tradicional e texto "alternativo", agregando este último à sala de aula. Assim, o professor pode contrapor textos tradicionais com os textos que os alunos afirmam serem instigantes para o grupo, trabalhando com temáticas afins, gêneros semelhantes (em uma obra clássica comparada com uma obra recente), ou outro eixo de debate. Novamente, lembrando Jobim (2009, p. 124), temos que "[...] a leitura na escola, desde que motivada por um tema adequado, pode gerar significados relacionados aos interesses e necessidades do aluno no momento, ajudando-o a encontrar-se em sua trajetória existencial." Jobim (2009) ainda destaca a importância de ir além do "entendimento" do texto, havendo "[...] sua crítica, sua avaliação, seu julgamento, sua colocação em confronto com outras produções textuais e realidades (especialmente a do próprio aluno)". (JOBIM, 2009 , p. 122, grifos nossos). É justamente essa aproximação com a realidade do aluno, em si, uma janela de oportunidades para melhor conjugar o interesse da escola com o do adolescente, no que tange à leitura literária.

Hoppen (2011), semelhante a Jobim (2009), conclui estudo acerca de interesses literários dos jovens dizendo que, para que a leitura literária efetivamente estimule seu leitor em um processo de subjetividade, como ferramenta valiosa para seu desenvolvimento, "[...] há de se levar em conta os gostos e interesses deste leitor, ou seja, há de ser uma escolha pessoal. Uma das formas de se fazer com que esta escolha aconteça é através do incentivo, da criação de oportunidades." (HOPPEN, 2011, p. 80). Ela acrescenta: “[...] é preciso que haja sensibilidade para se promover leituras que se relacionem com a vida dos jovens, leituras que façam sentido ao leitor primeiramente, e não às exigências do vestibular ou do que se tem como 'bons livros"”. (HOPPEN, 2011, p. 80). Ao que tudo indica, então, um dos caminhos pode ser esse: que a escola conceda atenção, respeito e espaço para as obras, autores e temáticas do universo de interesse dos alunos, de modo que só poderá agregar ao melhor andamento das aulas de literatura. 
No entanto, cumpre destacar que não há consenso entre estudiosos e críticos da área nessa questão. Enquanto Jobim e Hoppen, entre outros, sinalizam positivamente para a aproximação do interesse do adolescente (que inclui a literatura de massa) do interesse da escola, outros críticos, mais notoriamente Harold Bloom, condenam fortemente a literatura de massa que tanto atrai os jovens, rotulando-a como vazia e meramente mercatorial. Apesar da falta de consenso, observa-se uma tendência cada vez mais fortemente endossada a favor da observação do gosto próprio do aluno como um possível ponto de partida, independente de se tratar ou não de uma obra de literatura de massa.

\section{Considerações finais}

Diversos estudos publicados na edição de 2012 da pesquisa "Retratos da Leitura no Brasil" reiteram a importância da escola e do professor na formação do leitor e na motivação para a leitura, literária ou não. Failla (2012) comenta que os entrevistados lembram a figura do professor (e não mais da mãe) como principal agente na motivação para a leitura. Já Leite (2012, p. 67), na mesma publicação, reforça o papel da escola também no que tange ao "[...] tipo de material lido, frequência de leitura, gênero de texto lido, local de leitura e acesso aos livros". Ezequiel Silva (2012, p. 110), considerando esses fatos, acrescenta que para "[...] transformar para melhor a leitura no Brasil, teremos de transformar, também para melhor, a qualificação profissional e as condições de trabalho e de vida dos professores”. É curioso observar que, mesmo com a necessidade imediata de melhorias na formação dos professores e dos mediadores de leitura, nas abordagens metodológicas ao texto literário em sala de aula, e também nos próprios acervos das bibliotecas e no espaço dado à leitura no currículo, ainda assim o professor e a escola são fundamentais na formação do leitor. Esse é um fato que sem dúvida requer investigações futuras e específicas.

Almejando melhorias na questão leitora, várias são as propostas dos autores na obra "Retratos da Leitura no Brasil". Failla (2012) argumenta em prol da incrementação de programas para bibliotecas, formação de professores mediadores e de práticas leitoras em aula. Machado (2012, p. 61) defende que "[...] a escola deve ensinar que a leitura não se interrompe com a saída da escola. E as políticas públicas do setor devem apoiar”. E Silva (2012), por sua vez, detalha que 
[...] as políticas, os programas e as ações na esfera da leitura escolar devem estar voltados à união de esforços, complementaridade de propósitos, coletivização de responsabilidades, etc., no sentido de produzir mudanças substantivas na escola e no magistério, e assim levar a leitura para um patamar superior. (SILVA, 2012, p. 116).

Como podemos ver, muitos são os desafios no âmbito da leitura e, no que tange à questão específica da leitura literária e o adolescente de hoje, muitos também são os caminhos. Finalizamos esse estudo na esperança de ter colaborado para melhor entender o cenário da leitura adolescente, a partir de um grupo focal específico, bem como ter contribuído com ideias relevantes para harmonizar as relações entre os interesses do jovem e os da escola.

\section{REFERÊNCIAS}

BAMBERGER, R. Como incentivar o hábito de leitura. 7. ed. São Paulo: Ática, 2000.

BIASIOLI, B. L. As interfaces da literatura infanto-juvenil: panorama entre o passado e o presente. Terra Roxa e Outras Terras: Revista de Estudos Literários, Londrina, v. 9, p. 91-106, 2007.

CEREJA, W. R. Ensino de literatura: uma proposta dialógica para o trabalho com literatura. São Paulo: Atual Editora, 2005.

CHARTIER, R. A aventura do livro: do leitor ao navegador. São Paulo: Imprensa Oficial/ Editora Unesp, 2009.

COSSON, R. Letramento literário: teoria e prática. 2. ed. São Paulo: Contexto, 2011.

CUNHA, M. A. A. O acesso à leitura no Brasil: os recados dos "retratos da leitura". In: FAILLA, Z. (Org.). Retratos da leitura no Brasil 3. São Paulo: Instituto Pró-livro/ Imprensa Oficial, 2012. p. 83-91.

FAILLA, Z. Leitura dos "retratos": o comportamento leitor do brasileiro. In: FAILLA, Z. (Org.). Retratos da leitura no Brasil 3. São Paulo: Instituto Pró-livro/Imprensa Oficial, 2012. p. 19-54.

FARIA, M. A. O que pensam os adolescentes das histórias que lêem? Comunicação e Educação, São Paulo, v. 3, p. 30-35, 1995.

GOMES, I. V. Retrospectiva: o acesso ao livro e à leitura pelos jovens no Brasil. In: FAILLA, Z. (Org.). Retratos da leitura no Brasil 3. São Paulo: Instituto Pró-livro/Imprensa Oficial, 2012. p. 123-133. 
HOPPEN, N. H. F. O adolescente contemporâneo e seus interesses literários. Trabalho de Conclusão de Curso (Biblioteconomia) - Universidade Federal do Rio Grande do Sul, Porto Alegre, 2011.

JOBIM, J. L. A literatura no ensino médio: um modo de ver e usar. In: ZILBERMAN, R.; RÖSING, T. M. K. (Orgs.). Escola e leitura: velha crise, novas alternativas. São Paulo: Global, 2009. p. 113-137.

LEITE, S. A. S. Alfabetizar para ler. Ler para conquistar a plena cidadania. In: FAILLA, Z. (Org.). Retratos da leitura no Brasil 3. São Paulo: Instituto Pró-livro/Imprensa Oficial, 2012. p. 63-81.

LOURENÇO, D. S. Adolescentes leem, sim: a circulação da literatura estrangeira na escola. In: COLÓQUIO DA PÓS-GRADUAÇÃO EM LETRAS UNESP, II., 2010, Assis. Anais... Assis: UNESP, 2010. p. 372-383.

MACHADO, A. M. Sangue nas veias. In: FAILLA, Z. (Org.). Retratos da leitura no Brasil 3. São Paulo: Instituto Pró-livro/Imprensa Oficial, 2012. p. 57-62.

MAFRA, N. D. F. Leituras à revelia da escola. Londrina: EDUEL, 2003.

SILVA, E. T. A escola e a formação de leitores. In: FAILLA, Z. (Org.). Retratos da leitura no Brasil 3. São Paulo: Instituto Pró-livro/Imprensa Oficial, 2012. p. 107-116.

SILVA, R. J. Leitores e biblioteca escolar: do período Neolítico ao Hommo Sapiens Sapiens. Ensino em Re-Vista, Uberlândia, v. 20, n. 2, p. 357-366, jul./dez. 2013.

SOARES, N. F. A investigação participativa no grupo social da infância. Revista Currículo sem Fronteiras, v. 6, n. 1, p. 25-40, jan./jun. 2006.

ZILBERMAN, R. A escola e a leitura da literatura. In: ZILBERMAN, R.; RÖSING, T. M. K. (Orgs.). Escola e leitura: velha crise, novas alternativas. São Paulo: Global, 2009. p. 17-39.

Texto recebido em 12 de dezembro de 2014. Texto aprovado em 19 de junho de 2015. 